\title{
Applications of Nanomaterials for Water Quality Sustainability: Present Status and Future Trends
}

\author{
Oluwaseye S. Adedoja ${ }^{*}$, Yskandar Hamam ${ }^{1,2}$, Rotimi Sadiku ${ }^{3}$, Baset Khalaf ${ }^{2}$ \\ ${ }^{1}$ Department of Electrical Engineering/French South African Institute of Technology (F'SATI), Tshwane University of \\ Technology, Pretoria 0001, South Africa \\ ${ }^{2}$ ESIEE, 2 Boulevard Blaise Pascal, Noisy-le-Grand, Paris 93160, France \\ ${ }^{3}$ Department of Chemical, Metallurgy and Materials Engineering/ Institute for Nano Engineering Research (INER), Tshwane \\ University of Technology, Pretoria 0001, South Africa
}

Corresponding Author Email: princeturn205@yahoo.com

https://doi.org/10.18280/ijsdp.160215

Received: 23 April 2020

Accepted: 13 January 2021

\section{Keywords:}

multi-applications, water treatment, nanomaterial, sustainability, water desalination, water quality

\begin{abstract}
The diversity of water pollution and the depletion of some water resources have continued to linger despite several governmental and non-governmental programmes, especially in developing countries for water quality sustainability. This problem has reduced potable water availability, and it has increased water-related diseases in these countries. These problems are severe, mostly, in drought prone areas where water supplies and treatments are still at an infant stage. Hence, researchers are proposing the application of nanomaterials for water treatment and desalination. However, nanomaterials can also turn to be water pollutants that can threaten the public health if handled carelessly. This study, therefore, presents the applications and implications of nanomaterials in relation to water treatment and water quality. The review results highlighted the state-of-the-art and prospects of nanomaterials for water desalination and water quality production.
\end{abstract}

\section{INTRODUCTION}

Potable water is vital for human existence and it is a significant resource for several industries such as food and beverage, petrochemical, agricultural, oil and gas among others. Studies have shown that the consumption of contaminated water has severe consequences on plants, animals and human and may constitute serious health challenges and socio-economic nuisance [1-4]. Despite this information, there are lingering potable water crises across the world, for example, the most communities in developing countries are still struggling to meet the consistent demand of potable water supply for domestic and industrial use. The work of $\mathrm{Qu}$ et al. [5] attributed the decrease in available potable water to the increase in population size, urbanization, global climate change, and industrialization, while a United Nations report projected that water scarcity may increase by the middle of $21^{\text {st }}$ century [6]. This problem will decrease economic growth, increase poverty rate, and increase health-related diseases. Thus, it is possible that this unhealthy scarcity projection may astronomically increase in the near future [7]. Even though about $70 \%$ of the earth's surface is covered by water, a larger percent of it is not fit for human consumption in its raw form.

In some instances, the available water for consumption is not accessible to the public because most of the potable water is collected in underground water reservoirs. This problem has forced several households to resort to the use of untreated water, contaminated water, industrial waste water and seawater, especially, those in drought-prone zones. Even settlers that are sited along coastal areas are in dare need to process seawater because its high salinity delimits its usage, especially, for domestic uses. Some of these settlers have been able to use conventional water treatment methods to treat seawater, but these methods are unable to remove this salinity. To fill this gap between the available resources and the rising demand for potable water, desalination is inevitable. Desalination has been suggested as one of the means of providing potable water for many drought and coastal areas. It removes salts and minerals from seawater [8]. Desalination processes are broadly categorized into: thermal, mechanical, electrical, chemical and membrane-based technologies. Nonetheless, its extensive and intensive demands, such as: high energy consumption and intensive resource consumption, makes it economically unfit; and hence, there is a need for promising substitutes [9].

In spite the identification of desalination as a possible mean to cushion the shortage of water supply, with the tendency to provide potable water supplies, its processes such as: intensive energy demands require more research, in order to improve its efficiency and sustainability. The present desalination processes can be categorized into thermal and membrancebased techniques. Over time, the use of thermal processes has been explored by using excessive heat from power plants to desalinate seawater [10]. The operation of thermal processes is simple and its construction and the operational cost is relatively low. Despite these advantages, the excessive energy demands, environmental implications such as corrosion, and large space requirements in terms of land and materials are some of its disadvantages [11]. These technical challenges it 
poses led to emerging processes-membrane such as reverse osmosis (RO). Nowadays, RO has been widely embraced as an alternative to the traditional thermal processes in desalination technology [12]. Nair and Kumar [11] reported that, energy demand for the operation of $\mathrm{RO}$ is lower than that of the conventional thermal processes in their comparison analysis. Similarly, the space requirement for RO is lesser because of its compartment, unlike the thermal processes which is an added advantage. The use of semipermeable membranes with pore sizes ranging from 0.0001 to $0.001 \mu \mathrm{m}$ makes it finest available membrane. The size of its pore is capable to retain almost all molecules apart from water. This type of membrane can be made with the use of ceramic materials. Contrarily, forward osmosis (FO) uses semipermeable membrane and natural osmosis techniques which get rid of pressure, but its challenges remain ineffective membrane design.

Recent membrane techniques utilized available commercial polymetric materials such as thin film composite polyamide for RO and FO. The exploration of other membrane techniques with the use of poly-tetrafluorothylene (PTFE) and polyvinylidene-fluoride (PVDF) in membrane distillation (MD) have also been reported. More recently, membrane technologies such as: capacitive deionization (CDI) that uses carbon-based membrane for separating soluble has been examined. Interestingly, emerging advancement in engineering and material science has resulted to the discovery of nanomaterials with its application cutting across various discipline ranging from electronic, vaccine developmentmedical, and even desalination applications. Based on this, the current work aimed to review the applications of nanomaterials in desalination for water quality sustainability.

\section{NEED FOR NANOMATERIALS FOR WATER QUALITY SUSTAINABILITY}

The recent development and multi-applications of nanomaterials in environmental science and engineering, have positioned them at a forefront for water treatment, because they can bridge some of the identified and stated challenges associated with the existing water desalination and water treatment techniques. Their applications in this research domain have, therefore, rendered the present water treatment techniques that are centered on conveyance and the centralized system obsolete [13]. Nanomaterials' technologies are costeffective for water desalination and they tend to overcome some of the challenges of the present water treatment techniques. Apart from these benefits, they have the potential to serve as a new treatment approaches that can improve the socio-economic applications of water resources.

Nanomaterials are materials with dimensions lesser than $100 \mathrm{~nm}$. These materials retain novel dimension dependent properties unlike its larger associates. Thus, some of these materials have been used for water desalination and treatment applications in different areas - such as: adsorption, disinfection and microbial control, photo catalysis, and sensing and monitoring among others. Table 1 shows an overview of selected nanomaterials and their potential applications for water treatment and water desalination [13].

In recent time, carbon-based nanomaterials (CNMs) such as: carbon nanotubes (CNTs) and graphene, have significantly gained attention among researchers. This recognition can be attributed to nanomaterials' distinctive characteristics, such as: porosity, electrical conductivity, mechanical strength and stiffness [14]. Several authors have also positively ascribed to the distinct properties of these materials with possible improvement for water desalination and treatment $[15,16]$. For instance, zeolite, which is a cost-effective nanomaterial, has also been found suitable for water desalination [17, 18]. This material's penetrable structure helps in the removal of ions from saline water, thus, making it appropriate for water purification [19]. Aquaporin (AQP) is another nanomaterial that has also received positive recognition from the scientific community as an instrument for an improved water quality [20].

Table 1. Selected nanomaterial for water treatment and water desalination [13]

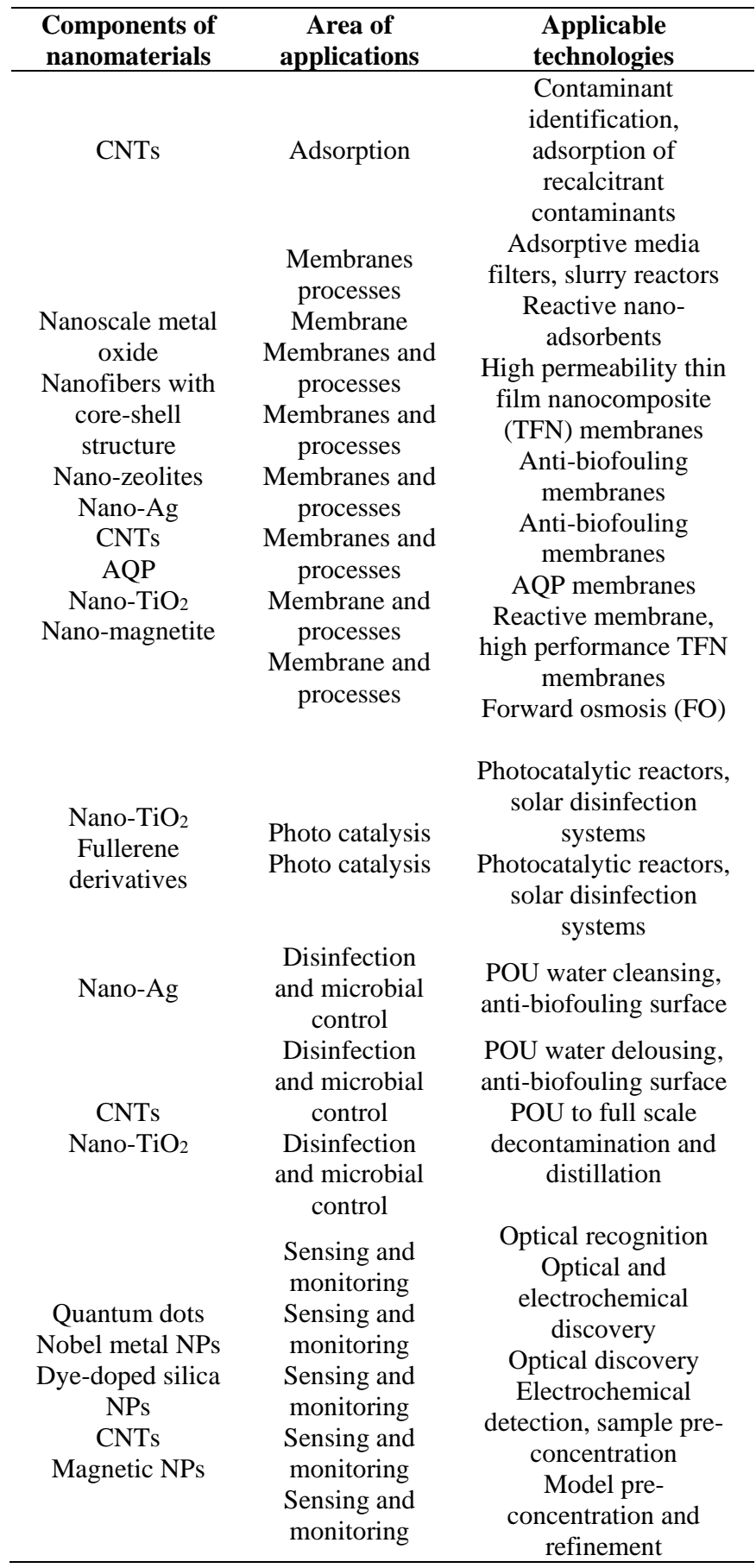

Tang et al. [21, 22] are among several researchers that have investigated the applications of nanomaterials for water 
treatment and desalination. As a contribution to knowledge in this domain, this study therefore, presents a comprehensive review of the applications of nanomaterials for water quality. The study presents a technical evaluation of some major nanomaterials' applications. Also, it discusses nanomaterials prospects and implications on public health and its socioeconomic implications in water treatment and desalination. The rest of the paper is structured as follows: Section 2 briefly highlights the need for nanomaterials for water quality sustainability. In section 3, applications of nanomaterials for an improved water quality are presented. Conclusions and future trends are provided in Section 4.

\section{APPLICATIONS OF NANOMATERIALS FOR AN IMPROVED WATER QUALITY}

This section briefly highlights some of the applications of nanomaterials for water treatment and desalination.

\subsection{Carbon Nanotubes (CNTs)}

Carbon nanotubes are carbon-based nanomaterials (CNMs) with diameters as small as $1 \mathrm{~nm}$. They belong to the allotropes of carbon sheets with one-atom-thick rolled, hollow tubeshaped nanostructure. These materials have very high strength-weight ratio when compared to any materials [23]. Apart from this attribute of CNMs, their exceptional adsorptive properties give them an edge when compared with materials that are contaminant in nature; such as heavy metals [24] and organic chemicals [25]. This attribute positioned them for diverse applications in desalination. CNTs have been used for different separation techniques, based on their ease of handling of membrane properties that can lead to enhanced permeable solute rejection, decreased polluting inclination, enhanced tensile strength and among others [26]. The report of an investigation conducted by Dumee et al. [27] established the use of CNTs for both reverse osmosis (RO) and forward osmosis (FO), while by Zhao et al. [28] enhanced the separation performance of FO membrane and minimize the diverged complications in FO procedure. Figure 1 shows a schematic diagram of a thin film composite (TFC) FO membrane model [28]. Bhadra et al. [29] proposed a carboxylation based CNTs and integrated carbon nanotube immobilized membrane (CNIM) in order to augment the efficacy of water desalination. Based on the integration of the carboxyl-functionalized CNTs. When their method was compared with a conventional approach, an improved desalination performance was observed. Multi-walled carbon nanotubes (MWCNTs) and $\mathrm{NH}_{2}$ functionalized multi-walled carbon nanotube $\left(\mathrm{NH}_{2}-\mathrm{MWCNT}\right)$ are among materials that are useful for enhanced desalination procedures [30]. Studies have shown that a single nanomaterial may be unable to provide the needful characteristics; hence, it is imperative to integrate some of these materials in a hybridized form [31]. Consequently, some researchers formulated hybrid materials and their results showed improved performance in aspects, such as: Chlorine and biofouling resistance, and elimination of salt [32]. Furthermore, Mishra and Ramaprabhu [33] used MWCNT based super capacitor to eliminate arsenic and desalinate seawater. This technique was exceptional because it uses 1 Volt direct current power supply to eliminate; $70 \% \mathrm{Na}$, $67 \% \mathrm{Mg}$, and $73 \% \mathrm{Ca}$ in 20 recurrence periods for the desalination of the seawater in question. Joseph et al. [34], reported the removal of natural organic matter (NOM) using a combination of coagulation and adsorption.

The performance of MD membrane with the integration of CNTs have also been reported [35, 36]. Bhadra et al. [29] reported that the flux performance of the traditional MD can be improved by integrating $0.00 \mathrm{mg} / \mathrm{cm} 2$ of MW.CNT into the MD membrane matrix over a 3-month period of time. The present MD membrane techniques still have some drawbacks which includes cost, low flux when compared to RO. Therefore, it is therefore necessary to fabricate an improved MD membrane in order to increase its usefulness and future applications in desalination processes [35].

CNTs enhances the implementation of separation techniques, and it has capability to remove salt from water without affecting its conductivity. However, some of its limitations is that, its requires a specialized synthesis procedure, which reduces the water flux and, it is expensive [28].

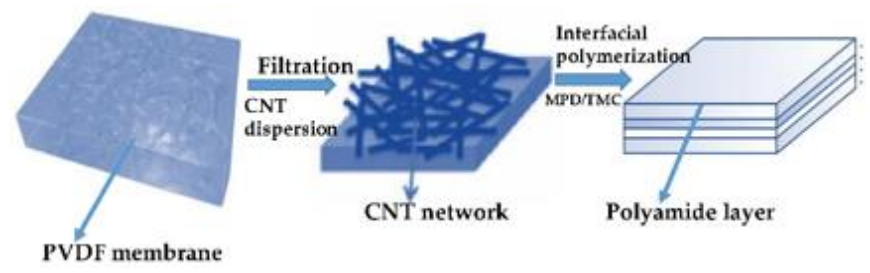

Figure 1. Schematic representation of the muti-layer FO membrane preparation procedure [28]

\subsection{Graphene}

CNTs cost limits their usage for many applications, despite the benefits of CNTs. Interestingly, graphene- a 2 dimensional sheet of allotrope carbon atoms arranged in hexagonal structure holds similar excellent properties as CNTs and it is economically suitable when compared to CNTs [37]. It is a low dimensional material with a high theoretical specific area of $2600 \mathrm{~m}^{2} / \mathrm{g}$, which doubled that of the finely activated carbon (AC) [38]. Its electrical conductivity is as high as $7200 \mathrm{~S} / \mathrm{m}$ at room temperature. These and more of the collective exciting properties of graphene, make it suitable for water desalination. The use of graphene sheet based super capacitor for water desalination was first reported by Mishra and Ramaprabhu [39]. The authors employed a functionalized hydrogen exfoliated graphene (f-HEG) sheets for the removal of sodium arsenate. The performance of graphene based super capacitor led to an enhanced commercial super capacitor based for water filter applications. Wang et al. [9] reported the use of a synthesized functional graphene nanocomposite (reduced graphite oxidate-resol such as material (rGO-RF)) as an electrode in a capacitive deionization (CDI) procedure. The addition of rGO-RF exhibited excellent results with an improved adsorption rate for the removal of sodium chloride $(\mathrm{NaCl})$ and an enhanced potable water sanitization when compared to the commercial activated carbon, AC. The procedure established by El-Deen et al. [40], was based on a synthesized graphene wrapped $\mathrm{MnO} 2$-nanostructured electrode for the removal of salt, which in turn, improved the water quality.

Graphene has a low energy consumption and a high adsorption capacity which is advantage. Notwithstanding, it gets saturated within a limited period [41]. 


\subsection{Zeolites}

Zeolites are crystalline aluminisilicate materials made up of alkali and alkali-earth metals. They have a 3 dimensional tetrahedral structure. Zeolites are used as cation exchangers because of their high adsorption capability. This property enables them to be used for water desalination [18, 42, 43], for example, their absorbent structures and channels make them fit as sorbent materials [44]. Wajima et al. [45] used modified natural zeolites (from Fukushima, Japan) to get rid of sodium chloride from seawater. Wibowo et al. [17] studied a modified natural zeolites performance during desalination of seawater (in Indonesia). Wajima et al. [45] and Wibowo et al. [17] showed that, natural zeolites are economically friendly as sorbent materials for seawater desalination. Also, Dong et al. [46] used a combined thin-film nanocomposite (TFN) RO membrane with $\mathrm{NaY}$ zeolites to remove salt from sea waters. Similarly, Kim et al. [18] reported an improved water quality when an animated template free zeolite (aTMA) was used for their investigations. Cho et al. [47] also obtained high water rejection with the use of $\mathrm{NaA}$ zeolites membrane. Other researchers have also reported an improved water quality when zeolites are used for water desalination and treatment [48, 49].

Zeolites are economically friendly and have a high adsorption capability. They are very useful for the detection and removal of toluene from saline water and they are mechanically steady for an elongated period when exposed to brackish solution [46]. However, zeolite's energy usage is high which is a drawback [17].

\subsection{Aquaporin}

Often, in seawater desalination, the separation membrane employed encompasses a dense polymeric film with the surface properties formed with a high chemical engineering procedure, primarily, intended and made for such applications. These synthetic membranes contain polymer sheets of various sizes of membrane pores where forces are necessary to push water out of the membrane and it is energy-consuming. Remarkably, AQPs, are pore-forming protein with resemblance to that of biological lipid bilayers. It is made-up of a six transmembrane $\alpha$-helices fixed in the cell membrane [50]. Under normal circumstances, AQP permits the formation of water molecules and a transport mode that leaves out other polar molecules. The possession of this low energy characteristic, mostly qualifies AQP for water purification technique. An improved permeability was reported by Bowen [51] with the use of biomimicry membrane. Kumar et al. [52] attained a higher permeability membrane when compared to an existing available commercial technique with the utilization of an integrated AQP into desalination membrane. Several other researchers have already reported on the feasibility and potential applications of AQP for water desalination and water quality attainment, based on their investigations [53, 54].

The excellent selective capacity and mechanical stability of an aquaporin are some of its benefits It, however, requires a specialized synthesis method and it is costly [52].

\section{CONCLUSIONS AND FUTURE TRENDS}

The scarce availability of water supply to meet the everincreasing water demand is a global challenge that has lingered for a while. This challenge has however put researchers on a sleepless mode in a search for ways to curtail the water challenge. Interestingly, desalination has been identified as an alternative to provide quality water. Notwithstanding, the traditional desalination techniques pose an environmental concern, and an improved technique for a sustainable performance is necessary. As such, the use of nanomaterials for desalination processes as a means to the provision of potable water is essential. Therefore, this study has presented some of the applications of nanomaterials. The explorations and applications of nanomaterials in the environmental and engineering studies have shown prospects.

In water desalination, nanomaterials have also found to be useful resources. As can be observed in this review, the use of nanomaterials for water desalination offers some technical benefits. The first is its capability to operate at lower energy consumption which also implies lower cost and lower emission when compared to the traditional desalination techniques. Another prospect is its availability and cost effectiveness. Some of these carbon-based nanomaterials such as graphite are inexpensive and can be processed as a membrane which is another advantage. Despite these benefits, the construction can still pose a technical challenge. Another benefits of nanomaterials such as CNTs is the possibility to operate at a lower pressure when compared to the conventional membranes, which is due to its favorable membrane surface characteristics.

Considerable researches have reported on the application of nanomaterials for desalination in terms of membranes. Even though, many studies have reported an improved performance when compared to the traditional method, there is still a concern on the salt rejection even with an increased flux. Therefore, further investigation on optimizing the performance of nanomaterials for membrane is essential. Another area of future studies is its economic viability of these materials in order to fully explore its potentials. As nanomaterials technology progresses, it is necessary to investigate their impacts on water quality and quantity. Nanotechnology is still at an infant stage, consequently, more effort should be devoted to bridging the theoretical and experimental processes to fully explore this technology in water treatment such as desalination.

Some of the drawbacks of this technology is the possibility of resulting to fresh environmental topics- such as: new classes of toxin, water pollution or any other associated environmental implications. In addition, this technology may also have an opposing magnitude on the personnel involved in the production and preparation of nanomaterials. Therefore, the rapid growth of the use of nanomaterials calls for an environmental and health assessment for both accidental and intentional exposure of the materials to the public. The thorough evaluation is essential for researchers and relevant practitioners to be more knowledgeable about the possible associated threat of nanomaterials. Also, most of the reported investigations are for short-term period, this has prevented the evaluation of possible performance drop and the probably associated maintenance challenges. Furthermore, both shortand long-term investigations effects of nanomaterials are recommended and should be curiously examined for sustainability.

\section{ACKNOWLEDGMENTS}

The authors would like to thank the Tshwane University of 
Technology, French South African Institute of Technology (F'SATI), and National Research Foundation (NRF) for providing enabling environment and financial support for this study. Opinions expressed, and conclusions arrived at, are mainly attributed to the authors.

\section{REFERENCES}

[1] Adedoja, O., Hamam, Y., Khalaf, B., Sadiku, R. (2018). Towards development of an optimization model to identify contamination source in a water distribution $\begin{array}{llll}\text { network. } & \text { Water, } & \text { 10: }\end{array}$ https://doi.org/10.3390/w10050579

[2] Adedoja, O.S., Hamam, Y., Khalaf, B., Sadiku, R. (2018). A state-of-the-art review of an optimal sensor placement for contaminant warning system in a water distribution network. Urban Water J., 15: 985-1000. https://doi.org/10.1080/1573062X.2019.1597378

[3] Adedoja, O.S., Hamam, Y., Khalaf, B., Sadiku, R. (2019). Development of a contaminant distribution model for water supply systems. Water, 11: 1510. https://doi.org/10.3390/w11071510

[4] Adedoja, O.S., Hamam, Y., Khalaf, B., Sadiku, R. (2019). Sensor placement strategies for contamination identification in water distribution networks: A review. WIT Trans Ecol Environ., 229: 79-90. https://doi.org/249/WRM190081

[5] Qu, X., Brame, J., Li, Q., Alvarez, P.J.J. (2012). Nanotechnology for a safe and sustainable water supply: Enabling integrated water treatment and reuse. Acc Chem Res., 46: 834-843. https://doi.org/10.1021/ar300029v

[6] Mohamed, M.B. (2011). Low cost nanomaterials for water desalination and purification. Final Tech. Rep., United Nations UNESCO.

[7] Organization, W.H. (2002). The world health report 2002: reducing risks, promoting healthy life. World Health Organization.

[8] Misdan, N., Lau, W.J., Ismail, A.F. (2012). Seawater Reverse Osmosis (SWRO) desalination by thin-film composite membrane current development, challenges and future prospects. Desalination, 287: 228-237. https://doi.org/10.1016/j.desal.2011.11.001

[9] Wang, Z., Dou, B., Zheng, L., Zhang, G., Liu, Z., Hao, Z. (2012). Effective desalination by capacitive deionization with functional graphene nanocomposite as novel electrode material. Desalination, 299: 96-102. https://doi.org/10.1016/j.desal.2012.05.028

[10] Mezher, T., Fath, H., Abbas, Z., Khaled, A. (2011). Techno-economic assessment and environmental impacts of desalination technologies. Desalination, 266: 263-273. https://doi.org/10.1016/j.desal.2010.08.035

[11] Nair, M., Kumar, D. (2013). Water desalination and challenges: The Middle East perspective: A review. Desalin Water Treat, 51: 2030-2040. https://doi.org/10.1080/19443994.2013.734483

[12] Lee, K.P., Arnot, T.C., Mattia, D. (2011). A review of reverse osmosis membrane materials for desalination development to date and future potential. J Memb Sci., 370: 1-22. https://doi.org/10.1016/j.memsci.2010.12.036

[13] Qu, X., Alvarez, P.J.J., Li, Q. (2013). Applications of nanotechnology in water and wastewater treatment. Water $\quad$ Res., 47: 3931-3946. https://doi.org/10.1016/j.watres.2012.09.058

[14] Li, X., Cai, W., An, J., Kim, S., Nah, J., Yang, D., et al. (2009). Large-area synthesis of high-quality and uniform graphene films on copper foils. Science, 324: 1312-1314. https://doi.org/10.1126/science. 1171245

[15] Goh, P.S., Ismail, A.F., Ng, B.C. (2013). Carbon nanotubes for desalination: Performance evaluation and current hurdles. Desalination, 308: 2-14. https://doi.org/10.1016/j.desal.2012.07.040

[16] Kotsalis, E.M., Walther, J.H., Koumoutsakos, P. (2004). Multiphase water flow inside carbon nanotubes. Int $\mathrm{J}$ Multiph Flow, 30: 995-1010. https://doi.org/10.1016/j.ijmultiphaseflow.2004.03.009

[17] Wibowo, E., Rokhmat, M., Murniati, R., Abdullah, M. (2017). Utilization of natural zeolite as sorbent material for seawater desalination. Procedia Eng., 170: 8-13. https://doi.org/10.1016/j.proeng.2017.03.002

[18] Kim, S.G., Hyeon, D.H., Chun, J.H., Chun, B.H., Kim, S.H. (2013). Nanocomposite poly (arylene ether sulfone) reverse osmosis membrane containing functional zeolite nanoparticles for seawater desalination. J Memb Sci., 443:

$10-18$. https://doi.org/10.1016/j.memsci.2013.03.065

[19] Xu, G.R., Wang, J.N., Li, C.J. (2013). Strategies for improving the performance of the polyamide thin film composite (PA-TFC) reverse osmosis (RO) membranes: Surface modifications and nanoparticles incorporations. Desalination, 328: 83-100. https://doi.org/10.1016/j.desal.2013.08.022

[20] Pendergast, M.M., Hoek, E.M.V. (2011). A review of water treatment membrane nanotechnologies. Energy Environ Sci., $\quad 4$ 1946-1971. https://doi.org/10.1039/C0EE00541J

[21] Tang, C.Y., Zhao, Y., Wang, R., Hélix-Nielsen, C., Fane, A.G. (2013). Desalination by biomimetic aquaporin membranes: Review of status and prospects. Desalination, 308: 34-40. https://doi.org/10.1016/j.desal.2012.07.007

[22] Cohen-Tanugi, D., Grossman, J.C. (2015). Nanoporous graphene as a reverse osmosis membrane: Recent insights from theory and simulation. Desalination, 366: 59-70. https://doi.org/10.1016/j.desal.2014.12.046

[23] Teow, Y.H., Mohammad, A.W. (2019). New generation nanomaterials for water desalination: A review. Desalination, 451: 2-17. https://doi.org/10.1016/j.desal.2017.11.041

[24] Gouda, A.A., Al Ghannam, S.M. (2016). Impregnated multiwalled carbon nanotubes as efficient sorbent for the solid phase extraction of trace amounts of heavy metal ions in food and water samples. Food Chem., 202: 40916. https://doi.org/10.1016/j.foodchem.2016.02.006

[25] Yang, K., Zhu, L., Xing, B. (2006). Adsorption of polycyclic aromatic hydrocarbons by carbon nanomaterials. Environ Sci Technol., 40: 1855-1861. https://doi.org/10.1021/es052208w

[26] Medina-Gonzalez, Y., Remigy, J.C. (2011). Sonicationassisted preparation of pristine MWCNT--polysulfone conductive microporous membranes. Mater Lett., 65: 229-232. https://doi.org/10.1016/j.matlet.2010.10.016

[27] Dumée, L., Lee, J., Sears, K., Tardy, B., Duke, M., Gray, S. (2013). Fabrication of thin film composite poly (amide)-carbon-nanotube supported membranes for enhanced performance in osmotically driven desalination systems. J Memb Sci., 427: 422-430. 
https://doi.org/10.1016/j.memsci.2012.09.026

[28] Zhao, X., Li, J., Liu, C. (2017). A novel TFC-type FO membrane with inserted sublayer of carbon nanotube networks exhibiting the improved separation performance. Desalination, 413: 176-183. https://doi.org/10.1016/j.desal.2017.03.021

[29] Bhadra, M., Roy, S., Mitra, S. (2013). Enhanced desalination using carboxylated carbon nanotube immobilized membranes. Sep Purif Technol., 120: $373-$ 377. https://doi.org/10.1016/j.seppur.2013.10.020

[30] Farahbakhsh, J., Delnavaz, M., Vatanpour, V. (2017). Investigation of raw and oxidized multiwalled carbon nanotubes in fabrication of reverse osmosis polyamide membranes for improvement in desalination and antifouling properties. Desalination, 410: 1-9. https://doi.org/10.1016/j.desal.2017.01.031

[31] Chai, P.V., Mahmoudi, E., Teow, Y.H., Mohammad, A.W. (2017). Preparation of novel polysulfone$\mathrm{Fe}_{3} \mathrm{O}_{4} / \mathrm{GO}$ mixed-matrix membrane for humic acid rejection. J Water Process Eng., 15: 83-88. https://doi.org/10.1016/j.jwpe.2016.06.001

[32] Azelee, I.W., Goh, P.S., Lau, W.J., Ismail, A.F., RezaeiDashtArzhandi, M., Wong, K.C., et al. (2017). Enhanced desalination of polyamide thin film nanocomposite incorporated with acid treated multiwalled carbon nanotube-titania nanotube hybrid. Desalination, 409: 163-170. https://doi.org/10.1016/j.desal.2017.01.029

[33] Mishra, A.K., Ramaprabhu, S. (2010). Magnetite decorated multiwalled carbon nanotube based supercapacitor for arsenic removal and desalination of seawater. J Phys Chem C., 114: 2583-2590. https://doi.org/10.1021/jp911631w

[34] Joseph, L., Flora, J.R.V., Park, Y.G., Badawy, M., Saleh, H., Yoon, Y. (2012). Removal of natural organic matter from potential drinking water sources by combined coagulation and adsorption using carbon nanomaterials. Sep Purif Technol., 95: 64-72. https://doi.org/10.1016/j.seppur.2012.04.033

[35] Dumée, L.F., Sears, K., Schütz, J., Finn, N., Huynh, C., Hawkins, S., et al. (2010). Characterization and evaluation of carbon nanotube Bucky-Paper membranes for direct contact membrane distillation. J Memb Sci., 351:

36-43. https://doi.org/10.1016/j.memsci.2010.01.025

[36] Dumée, L., Sears, K., Schü tz, J rg, Finn, N., Duke, M., Gray, S. (2010). Carbon nanotube based composite membranes for water desalination by membrane distillation. Desalin Water Treat, 17: 72-79. https://doi.org/10.5004/dwt.2010.1701

[37] Daer, S., Kharraz, J., Giwa, A., Hasan, S.W. (2015). Recent applications of nanomaterials in water desalination: A critical review and future opportunities. Desalination, 367:

$37-48$. https://doi.org/10.1016/j.desal.2015.03.030

[38] Stoller, M.D., Park, S., Zhu, Y., An, J., Ruoff, R.S. (2008). Graphene-based ultracapacitors. Nano Lett., 8: 3498-3502. https://doi.org/10.1021/nl802558y

[39] Mishra, A.K., Ramaprabhu, S. (2011). Functionalized graphene sheets for arsenic removal and desalination of sea water. Desalination, 282: 39-45. https://doi.org/10.1016/j.desal.2011.01.038

[40] El-Deen, A.G., Barakat, N.A.M., Kim, H.Y. (2014). Graphene wrapped $\mathrm{MnO}_{2}$-nanostructures as effective and stable electrode materials for capacitive deionization desalination technology. Desalination, 344: 289-298. https://doi.org/10.1016/j.desal.2014.03.028

[41] Feng, B., Xu, K., Huang, A. (2016). Covalent synthesis of three-dimensional graphene oxide framework (GOF) membrane for seawater desalination. Desalination, 394: 123-130. https://doi.org/10.1016/j.desal.2016.04.030

[42] Dahe, G.J., Teotia, R.S., Bellare, J.R. (2012). The role of zeolite nanoparticles additive on morphology, mechanical properties and performance of polysulfone hollow fiber membranes. Chem Eng J., 197: 398-406. https://doi.org/10.1016/j.cej.2012.05.037

[43] Ma, N., Wei, J., Liao, R., Tang, C.Y. (2012). Zeolitepolyamide thin film nanocomposite membranes: Towards enhanced performance for forward osmosis. $\mathrm{J}$ Memb Sci., 405: 149-157. https://doi.org/10.1016/j.memsci.2012.03.002

[44] Lenarda, M., Da Ros, M., Casagrande, M., Storaro, L., Ganzerla, R. (2003). Post-synthetic thermal and chemical treatments of H-BEA zeolite: Effects on the catalytic activity. Inorganica Chim Acta., 349: 195-202. https://doi.org/10.1016/S0020-1693(03)00032-X

[45] Wajima, T., Shimizu, T., Yamato, T., Ikegami, Y. (2010). Removal of $\mathrm{NaCl}$ from seawater using natural zeolite. Toxicol Environ Chem., 92: 21-26. https://doi.org/10.1080/02772240902762958

[46] Dong, H., Zhao, L., Zhang, L., Chen, H., Gao, C., Ho, W.S.W. (2015). High-flux reverse osmosis membranes incorporated with NaY zeolite nanoparticles for brackish water desalination. J Memb Sci., 476: 373-383. https://doi.org/10.1016/j.memsci.2014.11.054

[47] Cho, C.H., Oh, K.Y., Kim, S.K., Yeo, J.G., Sharma, P. (2011). Pervaporative seawater desalination using NaA zeolite membrane: Mechanisms of high water flux and high salt rejection. J Memb Sci., 371: 226-238. https://doi.org/10.1016/j.memsci.2011.01.049

[48] Garofalo, A., Carnevale, M.C., Donato, L., Drioli, E., Alharbi, O., Aljlil, S.A., et al. (2016). Scale-up of MFI zeolite membranes for desalination by vacuum membrane distillation. Desalination, 397: 205-212. https://doi.org/10.1016/j.desal.2016.07.010

[49] Hosseini, S.M., Rafiei, S., Hamidi, A.R., Moghadassi, A.R., Madaeni, S.S. (2014). Preparation and electrochemical characterization of mixed matrix heterogeneous cation exchange membranes filled with zeolite nanoparticles: Ionic transport property in desalination. Desalination, 351: 138-144. https://doi.org/10.1016/j.desal.2014.07.036

[50] Fu, D., Lu, M. (2007). The structural basis of water permeation and proton exclusion in aquaporins. Mol Membr Biol., 24: 366-374. https://doi.org/10.1080/09687680701446965

[51] Bowen, W.R. (2006). Biomimetic separations--learning from the early development of biological membranes. Desalination, 199: 225-227. https://doi.org/10.1016/j.desal.2006.03.053

[52] Kumar, M., Grzelakowski, M., Zilles, J., Clark, M., Meier, W. (2007). Highly permeable polymeric membranes based on the incorporation of the functional water channel protein Aquaporin Z. Proc Natl Acad Sci., 104:

20719-20724. https://doi.org/10.1073/pnas.0708762104

[53] Li, X., Chou, S., Wang, R., Shi, L., Fang, W., Chaitra, G., et al. (2015). Nature gives the best solution for desalination: Aquaporin-based hollow fiber composite 
membrane with superior performance. J Memb Sci., 494: 68-77. https://doi.org/10.1016/j.memsci.2015.07.040

[54] Homayoonfal, M., Akbari, A., Mehrnia, M.R. (2010). Preparation of polysulfone nanofiltration membranes by
UV-assisted grafting polymerization for water softening. Desalination, 263:

217-225. 